\title{
An Alternate Solvent for the Determination of Capsaicin Content in Chillies by HPLC Method
}

\section{Srinivasan $\mathrm{GV}^{1 *}$, Davis Thomas Daniel ${ }^{2}$, Soumya $\mathrm{KV}^{3}$ and Menon $\mathrm{KRK}^{4}$}

${ }^{1}$ Spices Board, Quality Evaluation Laboratory (QEL), Plot No. R-11, SIPCOT Industrial Area, Gummidipoondi, Chennai, Tamil Nadu, India

${ }^{2}$ Department of Chemistry, St. Stephen's College, New Delhi-110 007, India

${ }^{3}$ Spices Board, QEL, Tuticorin-628 004, Tamil Nadu, India

${ }^{4}$ Spices Board, QEL, Cochin-682 025, Kerala, India

*Corresponding author: Srinivasan GV, Scientist C, Spices Board, Quality Evaluation Laboratory (QEL), Plot No. R-11, SIPCOT Industrial Area, Gummidipoondi, Chennai, Tamil Nadu, India, Tel: +(91)-7200313143; E-mail: gv_srinivasan@rediffmail.com

Received: September 01, 2018; Accepted: September 10, 2018; Published: September 18, 2018

Copyright: (c) 2018 Srinivasan GV, et al. This is an open-access article distributed under the terms of the Creative Commons Attribution License, which permits unrestricted use, distribution, and reproduction in any medium, provided the original author and source are credited.

\begin{abstract}
An alternate solvent namely acetone has been proved effective for the determination of capsaicin content in chillies. Considering its less toxicity and easy to procure compared to methanol or rectified spirit, it can be used as the solvent for the determination of capsaicin content in chillies. The HPLC method adopted for the estimation of capsaicin content has been validated for specificity, linearity, recovery etc.
\end{abstract}

Keywords: Capsaicin; Capsaicinoids; TRPV1; Sensory neurons

\section{Introduction}

The chilli or hot pepper is a common plant used in various parts of the world due to its sensory properties. It is not only utilized as a coloring agent or a food additive but also is used for medicinal purposes. The hot flavor or pungency associated with chilies is due to the presence of Capsaicinoids. Capsaicinoids are alkaloid compounds present in the members of the plant family Capsicum. The amount of capsaicinoids ranges from $0.003 \%$ to $1 \%$ of the total weight of the plant according to the variety of hot pepper in consideration [1]. The group attached to the carbonyl group of the parent structure determines the properties of various Capsaicinoids [2]. The main capsaicinoid in chillies is capsaicin, followed by dihydrocapsaicin and nordihydrocapsaicin. The effect of these three compounds is much more pronounced than the other capsaicinoids such as nordihydrocapsaicin, homodihydrocapsaicin, homocapsaicin etc., which are present in relatively smaller amounts [3]. Figure 1 shows the parent structure of Capsaicinoids.<smiles>[R]C(=O)NCc1ccc(O)c(OC)c1</smiles>

Figure 1: Parent Structure of Capsaicinoids.

Capsaicin is a crystalline white powder with a melting point of $65^{\circ} \mathrm{C}$ and a boiling point of $200-210^{\circ} \mathrm{C}$ [4]. It was shown to be a mixture of at least five closely related vanillyl amides in a scientific study conducted by Bennett and Kirby [5]. Pure capsaicin has an extremely burning taste and a pungent odour. It has a solubility of $28.93 \mathrm{mg} / \mathrm{L}$ in water at $25^{\circ} \mathrm{C}$ (est) and is practically insoluble in cold water [4]. It is found to be soluble in alcohol, ether and Benzene. Capsaicin is found naturally in the fruits of capsicum plant and is present throughout the pod of the hot pepper. The structure comprises of a benzene ring and a long hydrophobic carbon tail with polar amide group with a molecular weight of 305.44. Figure 2 shows the structure of capsaicin.

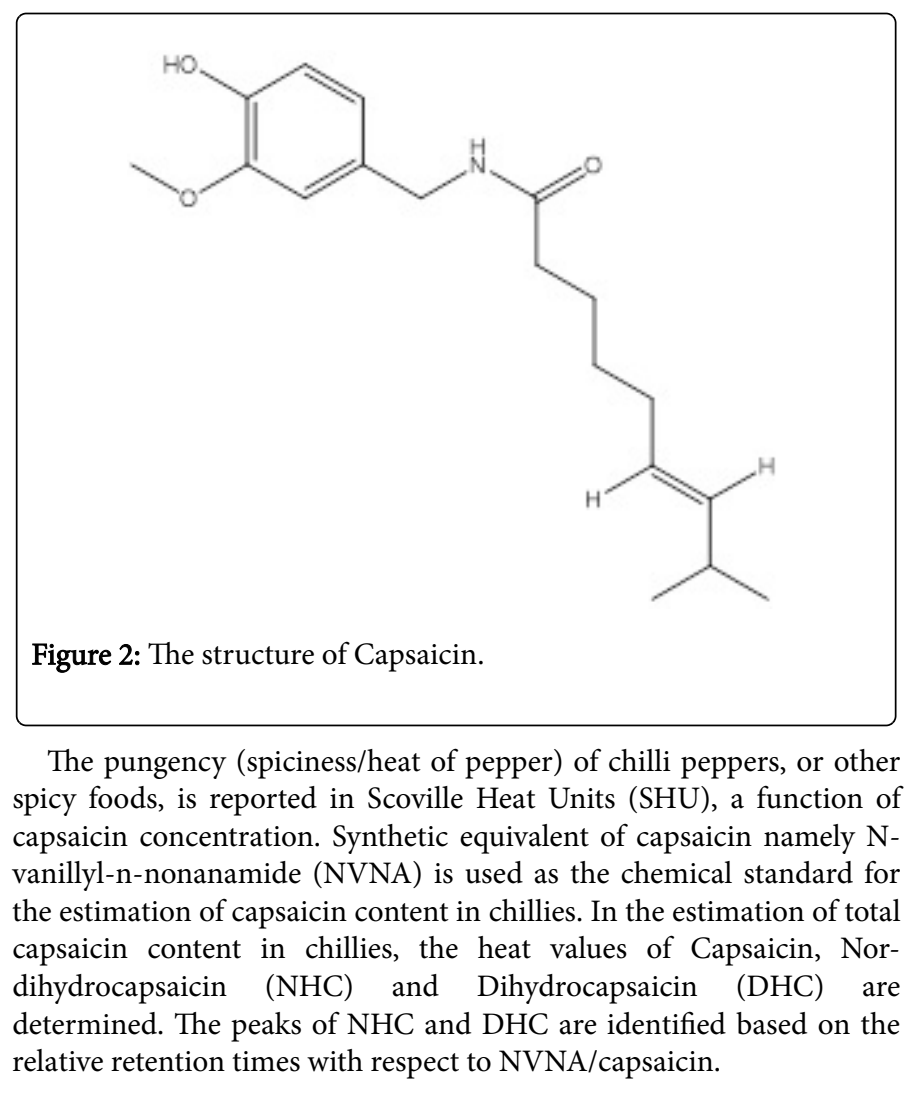


Conventionally, rectified spirit (95\% ethanol) is used for the capsaicin analysis. Owing to the difficulties in procuring rectified spirit (being a bonded chemical) and its low purity, an alternative solvent for the extraction of capsaicin from chilli peppers is important. In the present paper, a scientific study for a new solvent for the extraction of capsaicin is reported.

\section{Mechanism of action}

The chemical interaction of capsaicin with sensory neurons is responsible for the burning and painful sensation. Capsaicin belongs to the vanilloid family and binds to a receptor called the vanilloid receptor subtype 1 (TRPV1) [6]. TRPV1 is an ion channel-type receptor [7]. TRPV1, in its activated condition, permits cations to pass through the cell membrane and can also be activated with heat, protons and physical abrasion. The brain is signaled due to the resulting depolarization of the neuron. By binding to the TRPV1 receptor, the capsaicin molecule produces similar sensations to those of excessive heat or abrasive damage, explaining why the spiciness of capsaicin is described as a burning sensation.

\section{Results and Discussion}

The extraction of capsaicinoids using different solvents by following the extraction method (ASTA method), showed the SHU values for a particular chilli sample as given in Table 1 .

\begin{tabular}{|c|c|c|}
\hline Name of Solvent & SHU value & $\begin{array}{l}\text { Percentage } \\
\text { (Total Capsaicinoids) }\end{array}$ \\
\hline Petroleum Ether (PE) & 15800 & 0.10 \\
\hline Methanol & 31700 & 0.20 \\
\hline Rectified Spirit & 29600 & 0.18 \\
\hline Acetone & 31800 & 0.20 \\
\hline Acetonitrile & 28600 & 0.18 \\
\hline Methanol-Water $(80: 20)$ & 29600 & 0.18 \\
\hline Methanol-Water $(70: 30)$ & 29000 & 0.18 \\
\hline
\end{tabular}

Table 1: SHU Values for extraction with different solvents.

On repeating the analysis of different chilli samples with these solvents it was found that the SHU values from the different solvents are in the following order: acetone $>$ methanol $>$ rectified spirit $>$ methanol-water mixtures $>$ acetonitrile $>\mathrm{PE}$ (b.p. $\left.60-80^{\circ} \mathrm{C}\right)$. The $\%$ SHU obtained for different solvents on comparison with rectified spirit is given in Figure 3.

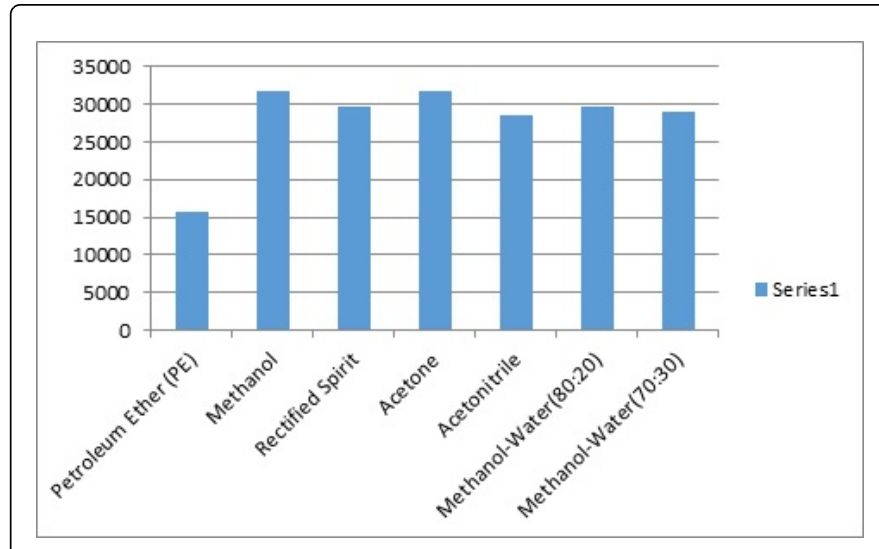

Figure 3: Chilli SHUs with different solvents.

From the results obtained, it was inferred that Acetone and Methanol showed SHU and percentage capsaicin values comparable or more than to that of Rectified Spirit. Thus, Methanol and Acetone were selected as extraction solvents for further studies and analysis of capsaicinoids. The capsaicin content in chillies was estimated using HPLC method (Figure 4).

The Chromatograms for the three solvents with highest SHU values is shown in Figure 5 (rectified spirit), Figure 6 (acetone) and Figure 7 (methanol).

After the analysis of SHU values and selection of Acetone and Methanol as extraction solvents on the basis of their respective SHU values, three different samples of chilies which were initially analyzed using rectified spirit and found to be showing high, moderate and low SHU values were selected for the analysis. All the three samples were ground finely and hot extraction was carried out with acetone, rectified spirit and methanol. Five sets of extraction were carried out with each solvent and each extract was injected twice in HPLC system. The average response of two injections was taken. The results were compared to that of Rectified Spirit and the respective values are given in Table 2.

\begin{tabular}{|l|l|l|l|}
\hline Sample Type & Solvent & SHU Value & Percentage Capsaicin \\
\hline Low SHU & Acetone & 10700 & 0.07 \\
\hline Low SHU & Rectified Spirit & 10000 & 0.06 \\
\hline Low SHU & Methanol & 11200 & 0.07 \\
\hline Moderate SHU & Acetone & 29600 & 0.18 \\
\hline Moderate SHU & Rectified Spirit & 28900 & 0.18 \\
\hline Moderate SHU & Methanol & 30000 & 0.19 \\
\hline High SHU & Acetone & 70900 & 0.44 \\
\hline High SHU & Rectified Spirit & 63300 & 0.39 \\
\hline High SHU & Methanol & 66300 & 0.41 \\
\hline *values are the mean of 5 replicates. & & \\
\hline
\end{tabular}

Table 2: SHU values for samples with low, moderate and high Capsaicin content. 
Page 3 of 4

The calculated percentage of capsaicin showed higher values in case of acetone and methanol when compared with the values obtained by using rectified spirit as the extraction solvent. It was also observed that both acetone and methanol showed good results during the analysis of samples with and high and low capsaicin content. Acetone and methanol showed higher SHU values for samples with high capsaicin content as compared to Rectified Spirit, which showed lesser SHU value for the same sample. With moderate capsaicin content, acetone showed more or less similar SHU values as rectified spirit while Methanol yielded a higher SHU value. With low capsaicin content, both acetone and methanol gave higher SHU values compared to rectified spirit.

Even though acetone and methanol are giving promising results, we have chosen acetone for further validation studies due to its less toxicity.

\section{Method validation studies}

Since the extraction of chillies with acetone showing higher yield in all the categories of chillies viz lower, moderate and higher SHUs, we have validated the extraction method with acetone. Baseline resolution of NVNA was obtained at $26 \pm 1^{\circ} \mathrm{C}$ using a C18 column $(250 \times 4.6 \mathrm{~mm}$ i.d; $5 \mu \mathrm{m}$ ) and an isocratic solvent system consisting of acetonitrilewater in the ratio $60: 40(\mathrm{v} / \mathrm{v})$ containing $1 \%$ acetic acid. The mobile phase was passed through $0.45 \mu \mathrm{m}$ PVDF filter and degassed before use. The flow rate was kept constant at $1.0 \mathrm{~mL} / \mathrm{min}$ and the detection was at $280 \mathrm{~nm}$. For calibration, standard solutions of NVNA were prepared at concentrations of 100, 200, 400, 600, 800 and $1000 \mu \mathrm{g} / \mathrm{Kg}$ using acetone as solvent. The standard solution was injected for 5 times and the average detector response was measured. The chilli extracts were assayed for 5 times and peak areas corresponding to capsaicin were compared with the standard NVNA, and peak areas of NHC and DHC were determined and thus the total capsaicin content of chillies were determined.

The validated parameters were specificity, linearity, repeatability, reproducibility, Limit of Quantification (LOQ), Limit of Detection (LOD), recovery, precision and accuracy according to the ICH guidelines [8]. Inter-day reproducibility was verified by analyzing six different concentrations of NVNA, each injected four times, and determining the relative standard deviation (\%RSD). The intra-day reproducibility was evaluated by the analysis of NVNA at two different concentrations (100 and $1000 \mu \mathrm{g} / \mathrm{Kg}$ ), four times a day on seven consecutive days and determining the \%RSD. For recovery studies, known concentration of NVNA was spiked in the chilli matrix with known SHU. Recovery was calculated by comparing the resulting peak area with the peak obtained from equal concentrations of NVNA and expressed as percentage of this ratio.

The calibration curve for NVNA was found to be linear over the range 0.1 to $0.01 \mathrm{mg} / \mathrm{ml}\left(\mathrm{r}^{2}=0.999\right)$. The linear regression equation for the calibration curve was $y=123612 x-78687$, where $y$ is the peak area ratio of NVNA and $x$ is the concentration of NVNA $(\mu \mathrm{g} / \mathrm{Kg})$. The average recovery was $88.10 \pm 0.5 \%$, while $\% \mathrm{RSD}$ in the inter-day and intra-day reproducibility was found to be $2.1 \%$ and $3.6 \%$, respectively. $\%$ RSD for repeatability was 1.1 . LOQ was found to be 3000 SHU and LOD was 900 SHU.

\section{Experimental Section}

\section{Materials and methods}

The dried red chilli pods without stems obtained from the storage facility of Quality Evaluation Laboratory of Spices Board, Chennai was powdered in the mixer grinder. $100 \mathrm{~g}$ of chilli powder was passed through Sieve ASTM No. $20(850 \mathrm{~mm})$. This sample was used for the estimation of capsaicin.

\section{Chemicals and reagents used}

The following reagents were used in the analysis:

(a) Rectified Spirit (b) Methanol (c) Acetone (d) Dichloromethane (e) Dichloroethane (f) Acetonitrile (g) Petroleum Ether (h) 80:20 Methanol-Water (i) 70:30 Methanol-Water. The solvents used were of HPLC grade.

\section{Instrumentation}

The study was carried out by using isocratic mobile phase flow rate of $1.0 \mathrm{~mL} / \mathrm{min}$. Before injecting the sample solutions into the HPLC system, the mobile phase was run through the system for more than 45 minutes in order to equilibrate the column. The mobile phase was a mixture of $60 \%$ Acetonitrile and $40 \%$ HPLC water containing $1 \%$ acetic acid. Shimadzu HPLC system with SPD-10 a detector was used for the analysis of capsaicin. The analytical column used was Prominence Enable reversed phase C18 column $(250 \mathrm{~mm} \times 4.6 \mathrm{~mm} \times$ i.d $5 \mu \mathrm{m})$. The computer system used is Acer with Windows 7 operating system (Microsoft Corp, Redmond WA) and data collection software LC-Solution from Shimadzu.

The test solutions were filtered through $0.20 \mu \mathrm{m}$ nylon-66 membrane before injection. NVNA standard was purchased from Sigma, Bangalore. All analyses were repeated for 5 times and averaged.

\section{Sample preparation}

Different samples of chilli pods were randomly chosen, mixed thoroughly and ground finely and then again mixed. The mixing procedure of the samples was done as follows:

1. Two samples from the lot are chosen and are ground together into fine chilli powder and kept aside.

2. The same process is continued till all the chilli samples are ground.

3. The chilli powder obtained from different chilli pods are then finally mixed together and passed through Sieve ASTM No. 20. The chilli samples were then stored in dry containers and kept for further analysis for capsaicinoids.

\section{Extraction and isolation}

The ASTA method was adopted for the analysis of capsaicinoids for the selection of most suitable solvent or solvent system for the analysis of capsaicinoids [9]. (a) $25 \mathrm{~g}$ of ground chilli sample was taken in a flat bottom flask. (b) $200 \mathrm{~mL}$ of extraction solvent (out of the reagents mentioned above) was added into the flask containing the sample. (c) The contents of the flask were refluxed 5 hours (d) Flasks were allowed to cool to room temperature. (e) Extracts were filtered through Whatman No.1 filter paper and collected in vials for HPLC analysis. 
Citation: Srinivasan GV, Daniel DT, Soumya KV, Menon KRK (2018) An Alternate Solvent for the Determination of Capsaicin Content in Chillies by HPLC Method. Nat Prod Chem Res 6: 342. doi:10.4172/2329-6836.1000342

Page 4 of 4

The ASTA method is used for all the extractions carried out with each solvent. The filtrate is injected into a HPLC system and quantification is done using NVNA standard. The NVNA standard chromatogram is given in Figure 4.

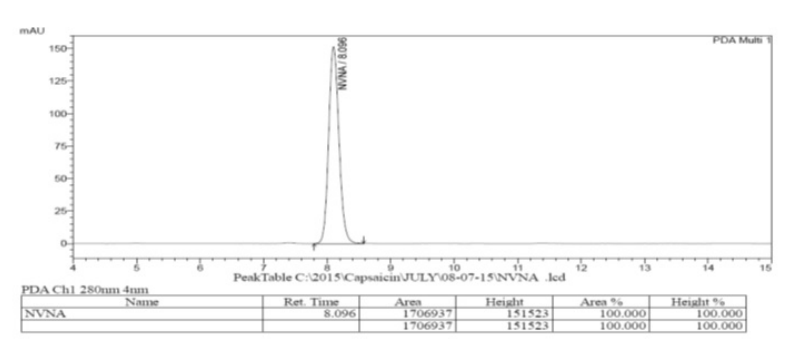

Figure 4: NVNA Standard Chromatogram.

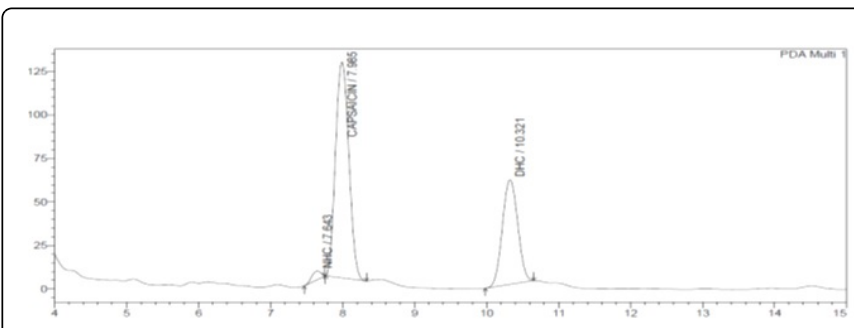

Figure 5: Chromatogram with Rectified spirit as extraction solvent.

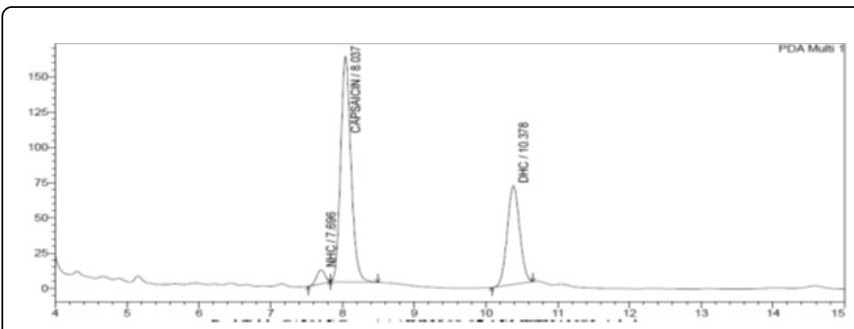

Figure 6: Chromatogram with acetone as extraction solvent.

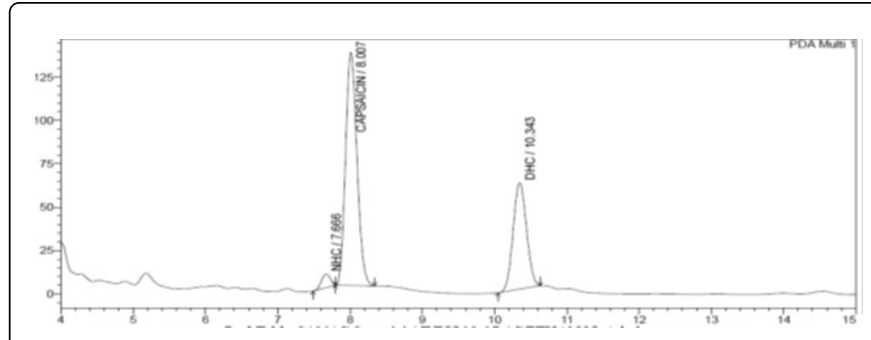

Figure 7: Chromatogram with Methanol as extraction solvent.

\section{Conclusion}

Since the extraction of chillies with acetone showing higher yield in all the categories of chillies viz lower, moderate and higher SHUs, we may choose Acetone as an alternate solvent for the extraction of chillies towards the determination of its capsaicin content. Moreover, the toxicity acetone is less compared to methanol and also it can be procured easily compared to rectified spirit.

\section{References}

1. Gerardo FB, Miguel P, Carmelo GB (2006) Pressurized liquid extraction of capsaicinoids from pepper. J Agric Food Chem 54: 3231-3236.

2. John Kailemia M (2009) Thesis on Studies of Capsaicinoids Contents of Locally Grown and Commercial Chilies Using Reversed-Phase High Performance Liquid Chromatography.

3. Kobata K, Kawamura M, Toyoshima M, Tamura Y, Ogawa S (1998) Lipasecatalyzed synthesis of capsaicin analogs by amidation of vanillylamine with fatty acid derivatives. Biotechnol Lett 20: 451-454.

4. National Center for Biotechnology Information. PubChem Compound Database. CID $=1548943$.

5. Bennett DJ, Kirby GW (1968) Constitution and biosynthesis of Capsaicin. J Chem Soc C, pp: 442-446.

6. Story GM, Crus Orengo L (2007) Feel the burn. American Scientist 95: 326-333.

7. Caterina MJ, Schumacher MA, Tominaga M, Rosen TA, Levine JD (1997) The capsaicin receptor: a heat-activated ion channel in the pain pathway. Nature 389: 81624.

8. Swartz ME, Krull IS (1997) Analytical method development and validation. NY, USA.

9. Official Analytical Methods of ASTA, (4th edn). 